\title{
Changes in Carbohydrates in Nursery-Grown Grapevine Rootstocks*
}

\author{
D. C. UYS AND C. J. ORFFER \\ Respectively from the Fruit and Fruit Technology Research Institute, Private Bag X5013, Stellenbosh 7600, and the
}

Department of Viticulture, Faculty of Agricultural Sciences, University of Stellenbosch, Stellenbosch 7600.

${ }^{*}$ Extract from a Ph.D. (Agric.)-thesis by the senior author, Stellenbosch 1981.

Accepted for publication: March 1983

\begin{abstract}
The utilisation and accumulation of sugar, starch and hemicellulose were studied in nursery-grown grapevine rootstocks. For an initial period lasting about 12 weeks all three components were utilised to varying degrees by the cuttings. Subsequently, starch and hemicellulose increased in the stem (original cutting) of the plant, while sugar remained low until the onset of winter. In the shoots, hemicellulose accumulation was very marked, whereas in the roots starch was the dominant carbohydrate component.
\end{abstract}

It has previously been shown that for a variety of deciduous fruits the development of the cutting during propagation, viz. the formation of roots and shoots, is among other factors dependent on their stored reserves of carbohydrates (Buttrose, 1966; Brutsch, 1971; Smith, 1972; Stassen, 1973).

With grapevines, Buttrose (1966) recorded an initially high starch (12\%) and a lower sugar (3\%) concentration in Sultana cuttings. After planting, starch decresed to $2 \%$, while sugar showed little loss. Hemicellulose also decreased, indicating that at least part of it could function as a reserve. Dry mass losses in the whole plant occurred until 17 days after bud first, at which stage photosynthetic production started to balance respiration. At this stage about $50 \mathrm{~cm}^{2}$ of leaf area had developed. Starch losses from the cuttings, however, continued for 14 more days.

Similarly, Schaefer (1978) in three graft combinations recorded initially higher starch than sugar values, with large losses of starch and smaller losses of sugar during the first 12-14 weeks after planting. From this time onwards, sugar remained constantly low, while excess carbohydrates were stored as starch. At the onset of winter, sugar increased at the cost of starch, but only in the shoots did sugar at any time exceed starch.

Kracke, Marangoni and Cristoferi (1980) studied the utilisation of starch and sugars in cuttings of 140R and Kober 5BB from dormancy and the swelling of the terminal bud sucrose concentration of fresh mass in the basal parts of the cuttings showed a very large decrease, while starch slightly increased. From then on until the formation of the first root, sucrose and starch were both utilised.

\section{MATERIALS AND METHODS}

Cuttings for rooting $(25-30 \mathrm{~cm}$ in length and $3-6 \mathrm{~cm}$ in diameter) of Jacquez (Vitis aestivalis - $V$. cinerea - $V$. vinifera; Galet, 1956) clone $1 / 3 / 11$ and Salt Creek (Ramsey) ( $V$. champini; Winkler et al., 1974) clone $5 / 19 / 5$ were collected at random from mature mother vines at the beginning of August 1975. The cuttings were stored in plastic bags at $0^{\circ} \mathrm{C}$ until planting on 19 August. Both clones have been tested free of leafroll, fleck and the fanleaf complex.

The experiment was laid out as a factorial arrangement of treatments. There were two factors, viz. cultivar (Jacquez and Salt Creek) and sampling date (19 August, 2, 16 and 30 September; 14, 28 October; 11, 25 November; 22 December, 22 January, 23 February, 22 March, 2 May and 23 July). The factors were replicated in 6 randomised blocks with 10 cuttings per replicate. Cuttings for sampling dates from 2 September onwards were planted on 19 August in plastered brick troughs filled with sand. Fertiliser at the rate of $5 \mathrm{~g} \cdot \mathrm{m}^{-2}$ (3:1:5(42) WS) was applied bi-weekly from planting until the end of February. Overhead micro irrigation was applied whenever necessary. The sampled plants were divided into roots, stem, shoots and leaves (where applicable). These portions were freeze-dried and ground to pass through a $0,4 \mathrm{~mm}$ sieve.

The procedure used for extraction of total alcohol soluble sugars was derived from methods applied by Marais (1965), Gaines (1973) and Stassen (1973 \& 1981). Sugars were extracted from the sample with $80 \%$ ethanol. After evaporation of the ethanol, the extract was cleared of proteins and pigments by the addition of balanced volumes of $\mathrm{Ba}(\mathrm{OH})_{2}$ and $\mathrm{Zn} \mathrm{SO}$. Di- and oligo-saccharides in the extract were acid-hydrolysed, followed by neutralisation with alkali. Remaining colour was removed with deactivated charcoal (Gaines, 1973).

In this alcohol-extracted residue starch was extracted by the taka-diastase method used by Marais (1969). This method entails incubation of the sample with takadiastase, clearing the filtrate with $\mathrm{Ba}(\mathrm{OH})_{2}$ and $\mathrm{Zn} \mathrm{SO}_{4}$, followed by acid hydrolysis, neutralisation, and decolouration with deactivated charcoal.

Hemicellulose was extracted from the starch-free residue by acid hydrolysis as used by Stassen (1973). This method was adapted from research work done by Turner (1969). Hydrolysis was followed by filtration, neutralisation and clearing of the filtrate as for sugar and starch.

Reducing sugars in the sample were determined with a Technicon Auto-Analyser by using a slightly modified version of the ferri-cyanide method applied by Bowen and Nonaka (1967). Glucose was used as a standard. 

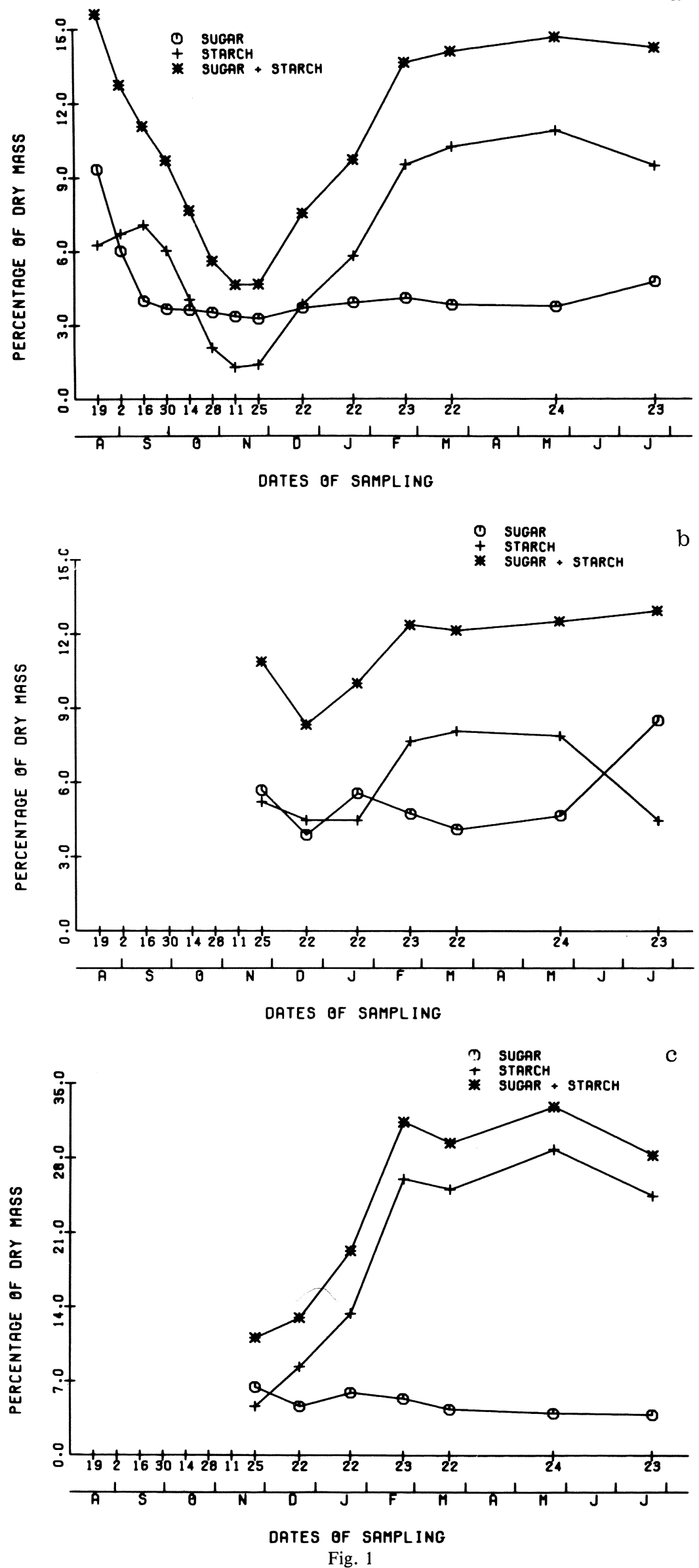

Changes in sugar and starch concentration of dry mass in the stem (a) shoots (b) and roots (c) of Jacquez vines in the nursery.

S. Afr. J. Enol. Vitic., Vol. 4. No. 1. 1983 

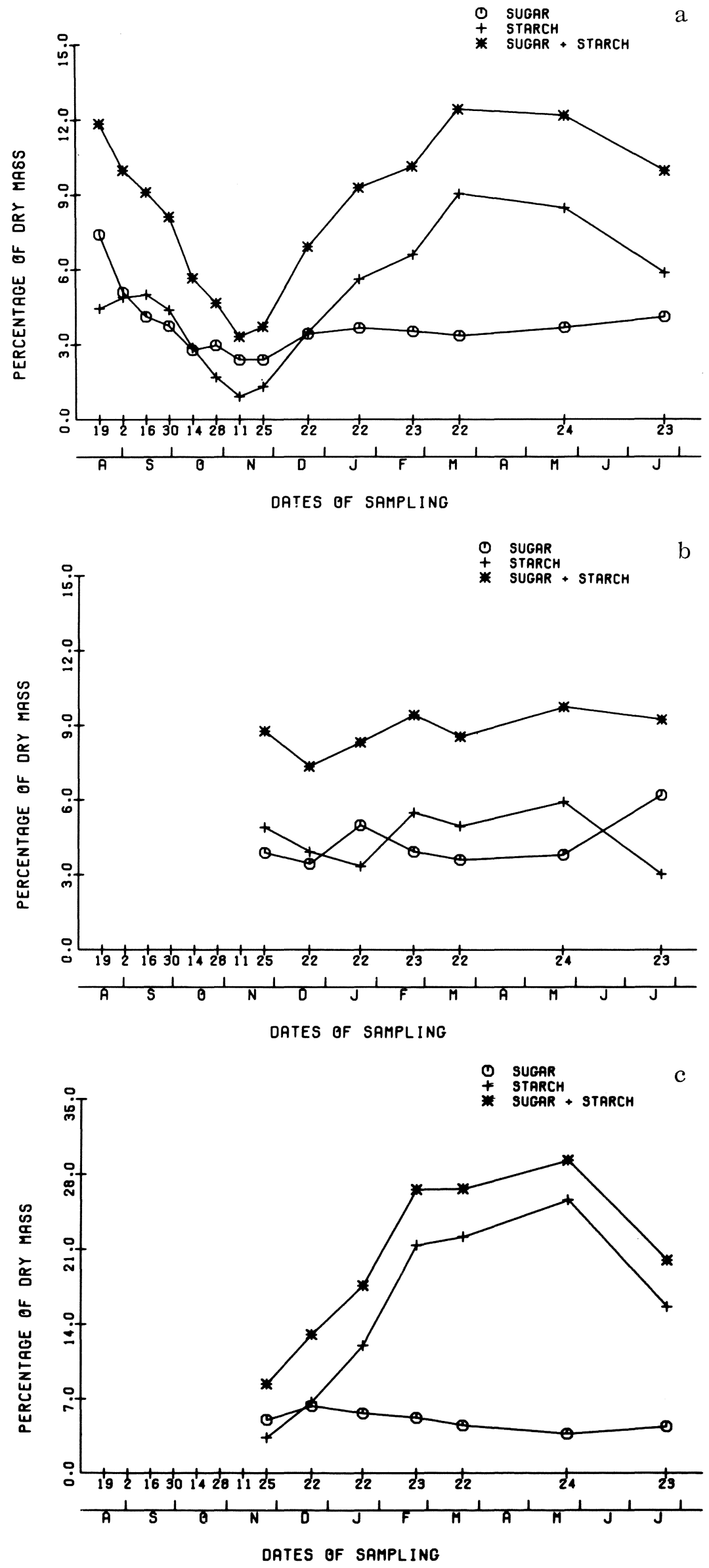

Fig. 2

Changes in sugar and starch concentration of dry mass in the stem (a) shoots (b) and roots (c) of Salt Creek vines in the nursery.

S. Afr. J. Enol. Vitic., Vol. 4. No. 1. 1983 


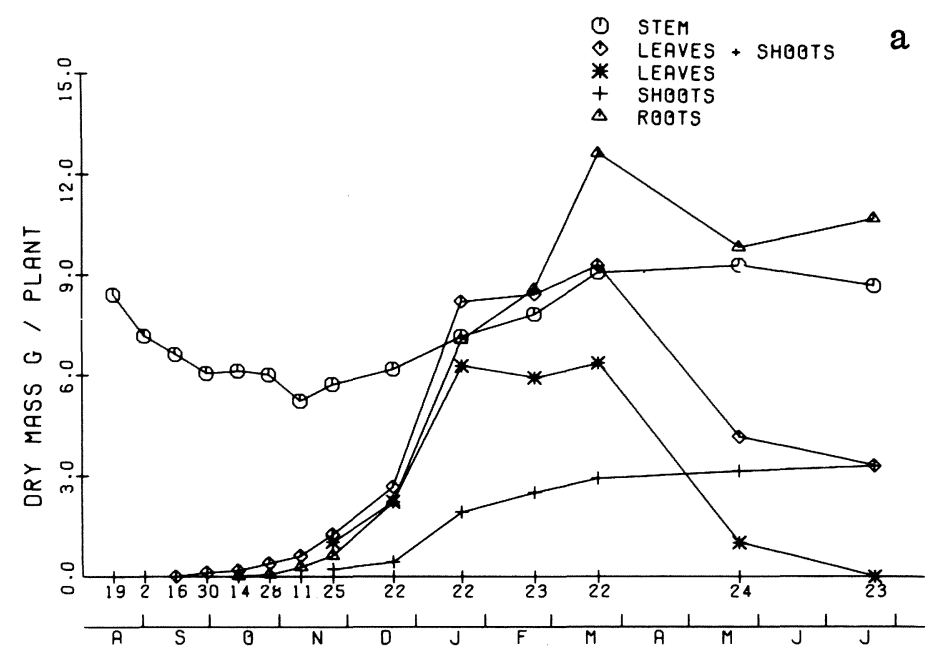

DATES OF SAMPLING
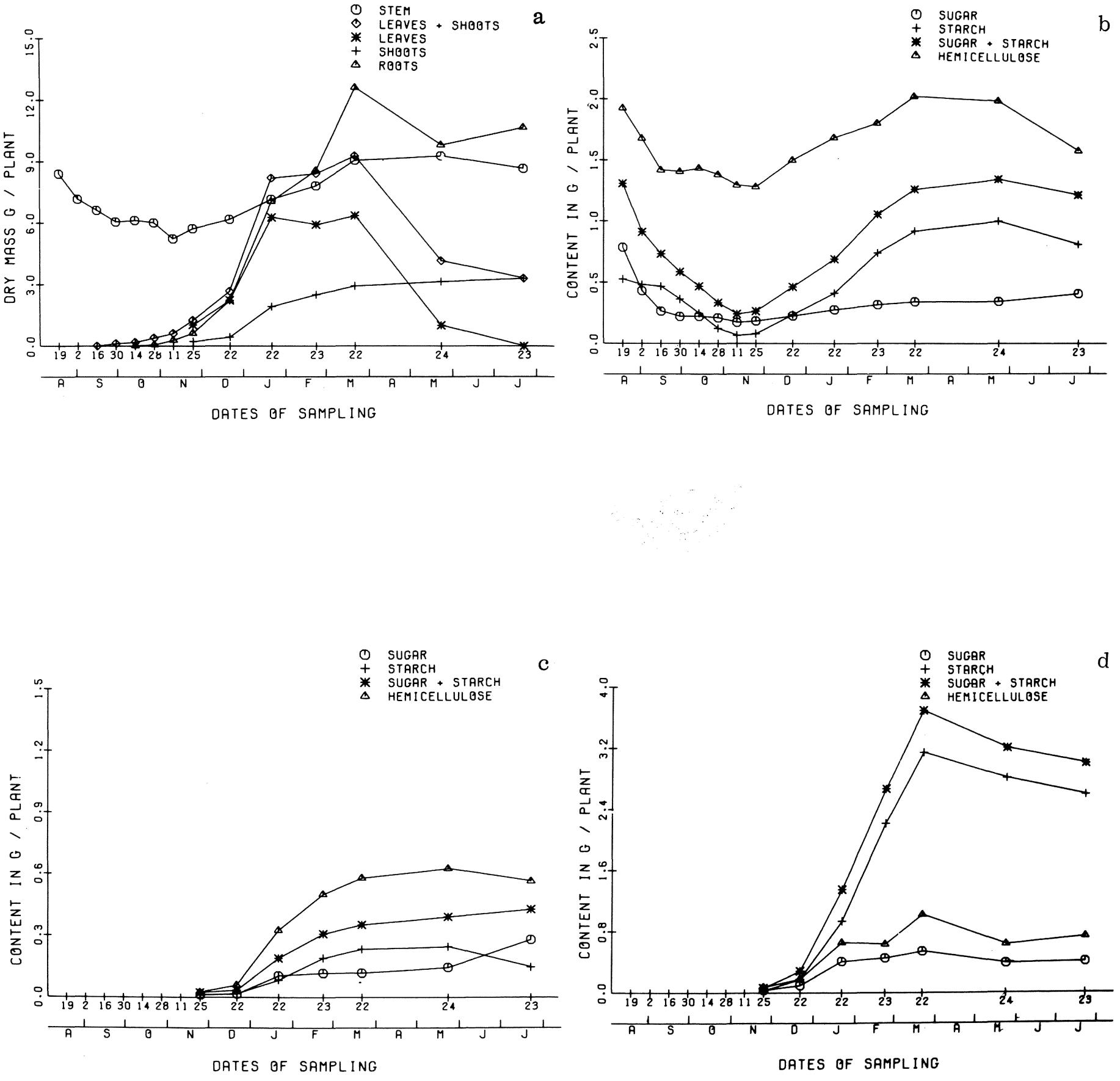

Fig. 3

Changes in dry mass of different plant parts (a) and sugar, starch and hemicellulose content in the stem (b) shoots (c) and roots (d) of Jacquez vines in the nursery. 


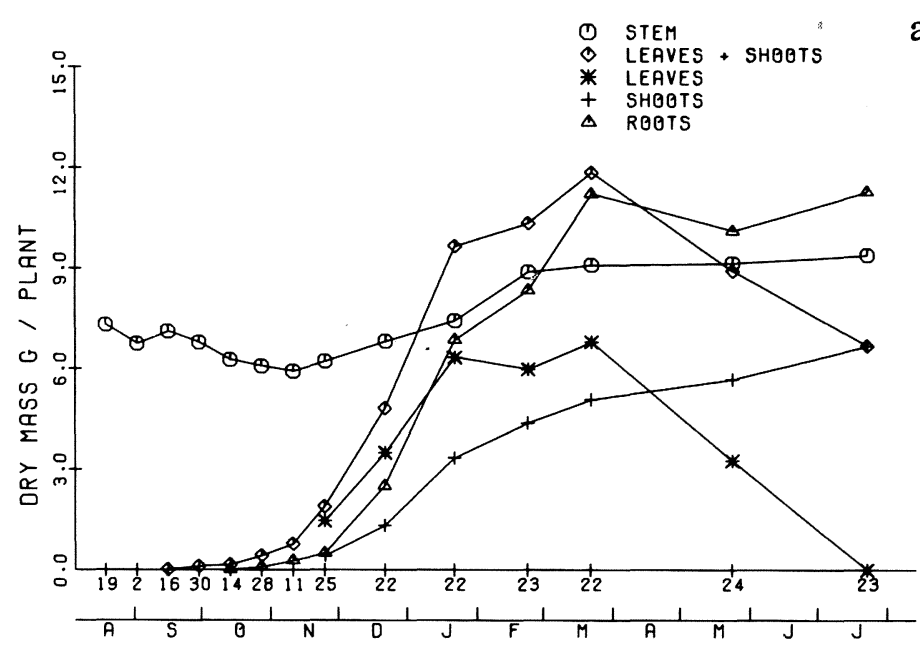

DATES OF SAMPLING

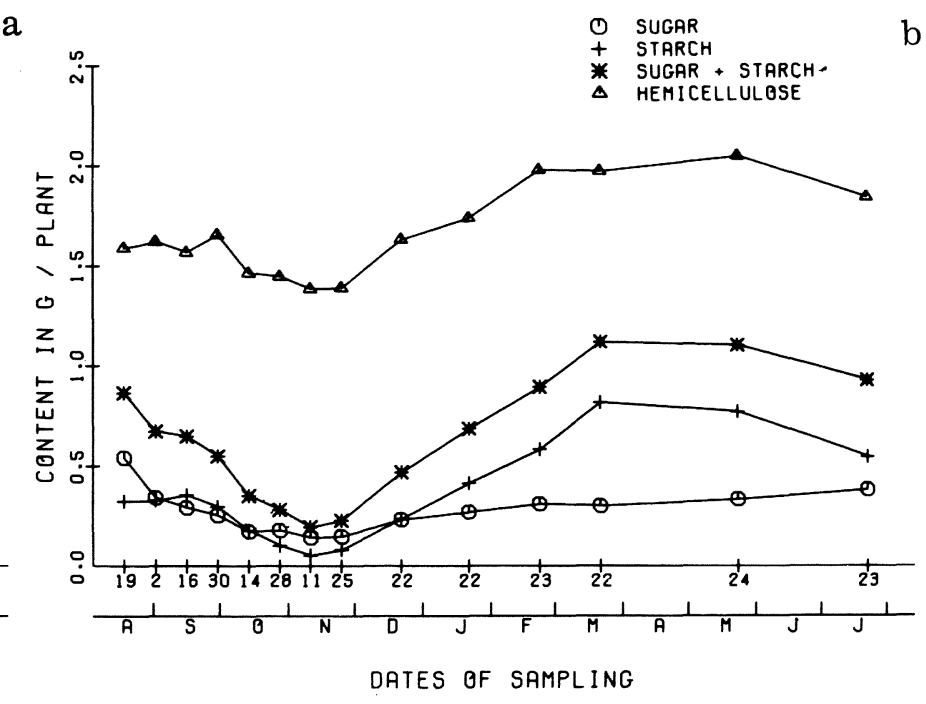

$\mathrm{b}$

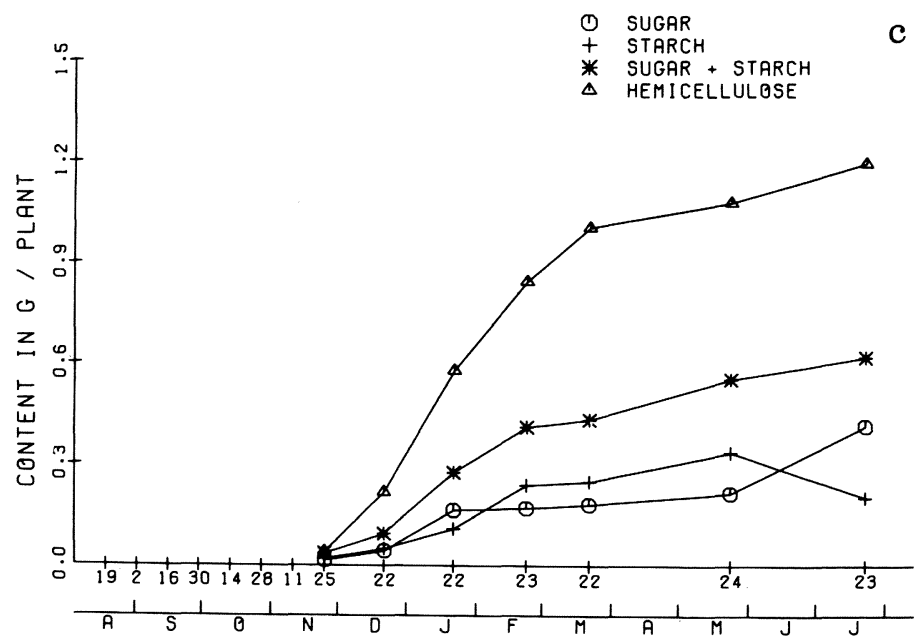

DATES OF SAMPLING

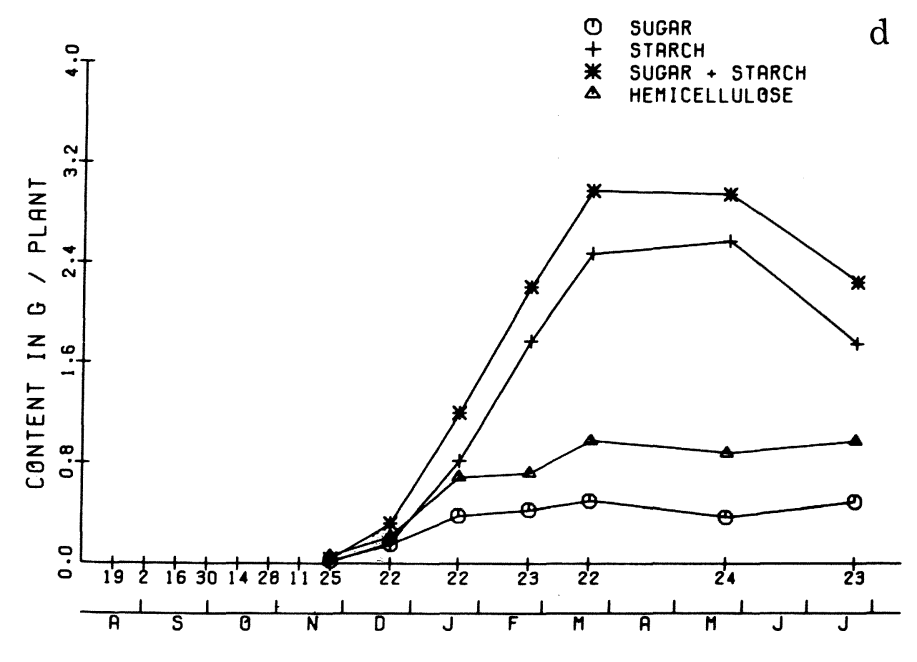

DATES OF SAMPLING

Fig. 4

Changes in dry mass of different plant parts (a) and sugar, starch and hemicellulose content in the stem (b) shoots (c) and roots (d) of Salt Creek vines in the nursery. 


\section{RESULTS AND DISCUSSION}

The changes in sugar and starch as percentage of dry mass during the growth of Jacquez and Salt Creek plants in the nursery are presented in Figs. 1 and 2.

Initially, sugar concentration in both cultivars was higher than that of starch, while the two fractions combined were higher in Jacquez $(15,6 \%)$ than in Salt Creek $(11,8 \%)$. These figures compare very well with those recorded in Sultana by Buttrose (1966) and in Delaware by Hosoi, Machida and Yoshida (1972). Initial hemicellulose concentration was $22,9 \%$ and $24,2 \%$ respectively.

The changes in the two cultivars were remarkably similar. They will be treated together, except where stated otherwise. In the stem part (original cutting) heavy losses in sugar occurred during the first four weeks, which coincided with a slight increase in starch. Following this period, sugar and starch decreased to a minimum at about 11 and 25 November. The cuttings were therefore partially dependent on their sugar and starch reserves for a period of 12 weeks after planting. This period corresponds very well with the results of Schaefer (1978) who, in three combinations, recorded minimum values in the sugar plus starch content in the scion and rootstock after 12 and 14 weeks, respectively. The patterns of sugar and starch changes during the first six weeks were also very simailar to those of sucrose (which was the predominant sugar) and starch changes recorded by Kracke et al. (1980).

Following the minimum values, starch in the stem increased rapidly, while sugar remained constant at just about $3 \%$. The increase in starch concentration coincided with the great expansion of the leaf area starting from 25 November (Figs. 3a, 4a). The excess carbohydrates (those which were not necessary for root, stem and shoot growth) formed during this period were therefore stored as starch. The increase in starch concentration in Jacquez stems was more pronounced than in Salt Creek. A possible explanation is that the latter exhibited more shoot growth and thus utilised a larger proportion of the synthesised carbohydrates. After 24 May, a conversion of starch to sugar occurred in the canes, resulting in a higher sugar than starch concentration on 23 July.

Accumulation of starch in the roots took place at the same stage as in the stem, and reached a maximum concentration of $28,9 \%$ in Jacquez and $25,7 \%$ in Salt Creek on 24 May. The slight decrease in starch concentration in Jacques stems from 22 February to 22 March, and the less pronounced increase with Salt Creek during the same period, coincided with a period of rapid root growth (Figs. 3a, 4a). Sugar concentration in the roots remained low throughout the season, whilst no conversion of starch to sugar occurred during winter. The latter is in agreement with findings in California (Winkler \& Williams, 1945).

The dry mass changes in the different plant parts are presented in Figs. 3a and 4a. In both cultivars the dry mass of stems decreased during the first 12 weeks until 11 November, after which it increased until the last sampling date on $23 \mathrm{July}$, when it was only slightly higher than the initial mass of the cutting.

Although shoot and leaf growth started before root growth, the final dry mass of the roots exceeded that of the former, with ratios of approximately 3,2:1 for Jacquez, and 1,7:1 for Salt Creek. Salt Creek showed considerably more shoot growth than Jacquez. In both cultivars leaf dry mass increased until 22 March and up to that time exceeded the dry mass of the shoots. After this date abscission of leaves commenced, starting earlier in Jacquez that in Salt Creek. The temporary decrease in leaf dry mass on 23 February is considered to be due to the loss of smaller, older leaves because of hot and dry weather conditions at that stage.

Because of the large increase in dry mass in the shoots and roots during the season, the results when expressed as concentration of dry mass do not provide a complete picture of the carbohydrate changes taking place in these parts. Furthermore, in the stem the relatively large initial losses of sugar and starch also have an effect on the dry mass, and could mask smaller changes of a substance such as hemicellulose. This disadvantage of expressing results on a percentage basis may be overcome by the use of the actual content per plant part, as indicated in Figs. 3b-d and 4b-d.

Sugar and starch content in the stem of both cultivars followed much the same patterns as the graphs expressing percentage. Simultaneously with sugar and starch utilisation, part of the hemicellulose was also depleted, which is in agreement with earlier findings (Buttrose, 1966). Following the lowest starch and hemicellulose contents, which occurred almost simultaneously, hemicellulose increased concomitantly with the increase in starch. This increase in hemicellulose may be regarded as the result of a replacement of that depleted earlier, as well as the formation of cell walls in new growth of the stem. Apparently, at least part of the hemicellulose fraction must be regarded as a reserve carbohydrate.

Hemicellulose accumulation was very marked in the shoots, whereas in the roots starch prevailed as the dominant of the three carbohydrate components studied. In the roots, the most striking feature was the very rapid increase in starch content between 25 November and 22 March. The difference in root to shoot dry mass ratio between Jacquez and Salt Creek was inevitably also reflected in the carbohydrate content of those parts. This can be seen clearly in Figs. 3c, d and $4 c, d$.

The percentage distribution of the combined values of the two most important reserve carbohydrates in the plant, viz. sugar and starch, on 23 July, is shown in Table 1.

TABLE 1

Distribution of sugar and starch in the plant on 23 July (\%)

\begin{tabular}{llcl}
\hline & Stem & Shoots & Roots \\
Jacquez & 16,2 & 9,1 & 64,7 \\
Salt Creek & 24,5 & 16,2 & 59,3 \\
\hline
\end{tabular}

These results suggest that excessive removal and shortening of roots on rooted vines prior to planting may be detrimental to the carbohydrate status of the vine. Severe pruning of shoots (canes) would most probably have less effect. 


\section{LITERATURE CITED}

BOWEN, J. E. \& NONAKA, T., 1967. Automatical analysis in sugar cane crop control. Automn. anal. Chem. New York: Technicon Instrum. Corp.

BRUTSCH, M., 1971. Rooting and early growth of Carya illinoensis (Wang.) K. Koch stem cuttings. M.Sc. (Agric.) Thesis, Univ. Natal.

BUTTROSE, M. S., 1966. Use of carbohydrate reserves during growth from cuttings of grapevine. Aust. J. biol. Sci. 19, 247-256.

GAINES, T. P., 1973. Automated determination of reducing sugars, total sugars and starch in plant tissue from one weighed sample. J. Ass. off. agric. Chem. 56, 1419-1424.

GALET, P., 1956. Les hybrides Producteurs Directs. In: Cepages et Vignobles de France, Tome 1. Montpellier: Paul Déhan.

HOSOI, T., MACHIDA, H. \& YOSHIDA, R., 1972. Changes in the nutritional constituents in cuttings during propagation. II Changes in nitrogen and carbohydrate contents in hardwood cuttings of grapevines. J. hort. Ass. Japan 41, 127-132.

KRACKE, H., MAGANGONI, B. \& CRISTOFERI, G., 1980. Proceedings of the UCD Grape and Wine Centenary, 1980.

MARAIS, J. P., 1965. The determination of available carbohydrates in grasses. M.Sc. (Agric.) Thesis, Univ. Natal.
MARAIS, J. P., 1969. The Weinman method for determination of total available carbohydrates in plant material containing starch. Agroplantae 1 , 47-50.

SCHAEFER, H., 1978. Der Proteinstoffwechsel der Jungreben in der Rebschule. Weinberg Keller 25, 331-352.

SMITH, I. E., 1972. Further studies on the physiology of rooting and survival of Carya illineonsis (Wang.) K. Koch stem cuttings. M.Sc. (Agric.) Thesis, Univ. Natal.

STASSEN, P. J. C., 1973. Koolhidraatreserwes en mobilisasie in Malus domestica Borkh. M.Sc. (Afric.) Thesis, Univ. Stellenbosch.

STASSEN, P. J. C., 1981. Seasonal changes in carbohydrate fractions of young Kakamas peach trees. Agroplantae 13, 47-53.

TURNER, W. W., 1969. Enzymatic determination of starch feeds, feed ingredients, and feces. J. Ass. off. agric. Chem. 52, 956-958.

WINKLER, A. J. \& WILLIAMS, W. O., 1945. Starch and sugars of Vitis vinifera. Pl. Physiol., Wash. 20, 412-429.

WINKLER, A. J., COOK, J. A., KLIEWER, W. M. \& LIDER, L. A., 1974. General Viticulture, 2nd ed. Berkeley, Los Angeles \& London: University of California Press. 